\title{
On Speculative Enactments
}

\author{
Chris Elsden $^{1}$, David Chatting ${ }^{1}$, Abigail C. Durrant ${ }^{3}$ Andrew Garbett $^{1}$, \\ Bettina Nissen $^{2}$, John Vines ${ }^{3}$, David S. Kirk ${ }^{3}$, \\ Open $\mathrm{Lab}^{1}$ \\ Newcastle University \\ Newcastle upon Tyne, UK \\ \{c.r.elsden; david.chatting; \\ a.garbett\}@ncl.ac.uk
}

\begin{abstract}
Speculative Enactments are a novel approach to speculative design research with participants. They invite the empirical analysis of participants acting amidst speculative but consequential circumstances. HCI as a broadly pragmatic, experience-centered, and participant-focused field is well placed to innovate methods that invite first-hand interaction and experience with speculative design projects. We discuss three case studies of this approach in practice, based on our own work: Runner Spotters, Metadating and a Quantified Wedding. In distinguishing Speculative Enactments we offer not just practical guidelines, but a set of conceptual resources for researchers and practitioners to critique the different contributions that speculative approaches can make to HCI discourse.
\end{abstract}

\section{Author Keywords}

Design Methods; Speculative Design; Data-Driven Life; Design Fiction; Critical Futures; Research through Design

\section{ACM Classification Keywords}

H.5.m. Information interfaces and presentation (e.g., HCI): Miscellaneous;

\section{INTRODUCTION}

Human-Computer Interaction (HCI) is a future-oriented field with a pragmatic drive to discern and shape preferable futures of technology use in everyday life. 'Envisioning' possible futures - through a mixture of fiction, forecasting, imagining and extrapolating - is a central concern for $\mathrm{HCI}$ research [27,43,67]. In recent years, an integration of Research through Design (RtD) [34,84], Futures work $[6,10,17]$, and Critical and Speculative Design [28,29] has seen HCI turn to envisioning more critically, and develop a range of speculative methods. This paper critically reflects on the use of speculative methods in HCI. Through three examples of our own work - Runner Spotters, Metadating

\section{(c) (7)}

This work is licensed under a Creative Commons Attribution International 4.0 License.

Copyright is held by the owner/author(s).

CHI 2017, May 06-11, 2017, Denver, CO, USA

ACM 978-1-4503-4655-9/17/05.

http://dx.doi.org/10.1145/3025453.3025503

All data accompanying this publication is directly available within the publication. and a Quantified Wedding - we propose an experiencecentered approach to speculative practice.

Speculative design research goes beyond envisioning as prototyping [24] or scenarios [19], and instead relies on imagination and fiction to develop critical dialogues and discourse about new, alternative and future paradigms of technology use. The 1960's Italian Radical Design movement [15], Archigram's hypothetical architectural projects [23], the humor of chindōgu [42], through to Dunne \& Raby's Critical and Speculative Design [28,29] demonstrate a critical and design-led lineage to this field. Speculation and opening up critical dialogue around technological alternatives was also a founding quality of Scandinavian participatory design $[11,55]$.

Speculative approaches in HCI have since been deployed for: critique $[8,9,16,25,47,52,56]$; exploring emerging 'upstream' technology [e.g., 11,12,25,39,44,52]; and opening up areas for future research [e.g.,9,40,57]. This selection of work exemplifies speculation as a form of Research through Design; and as a form of provocation that "create[s] a discursive space" [48]. Bleecker's Design Fiction [6] in particular has come to typify this approach by "making things that tell stories". Here, speculative design work is undertaken to produce and present artifacts and materials (or 'diegetic prototypes'), which communicate a story-world (or diegesis), and are embedded with its values.

However, as these speculative practices mature, we need to articulate more clearly their role, and the nature of the knowledge contributions offered to $\mathrm{HCI}$ - a fundamentally applied, participatory and experience-centered field. We argue that, beyond generating discourse, there is a need to "engage people more viscerally in futures conversations" [18]. Practically, there is more we can learn from the way people can interact with, and experience, speculation.

In this paper, we seek to take on this challenge. We question how speculation can be put to work in the world and engage people on an experiential level. We critically reflect on three of our own speculative design projects, presenting 'Speculative Enactments' as a complementary and novel approach to speculative design. We propose going beyond stimulating discourse about speculation, towards developing means to act amidst it. These enactments are a way to generate compelling and, crucially, 
consequential moments of social interaction, which invite the qualitative HCI study of plausible future circumstances and technologies with participants. Our paper is structured around two central contributions:

1) The introduction of Speculative Enactments as a novel and complementary approach to speculative design research that prioritizes participant experience with speculation, and invites broader empirical analysis.

2) A critical reflection on how speculative methods are used, and interacted with to generate experiences that go beyond discourse; and the knowledge (or forms of knowledge) this can produce for HCI.

\section{SPECULATIVE ENACTMENTS: AN OVERVIEW}

Speculative Enactments constitute an effort to meaningfully enact elements of possible futures with participants. Speculative Enactments work by making speculation matter to these participants; we suggest they become consequential to participants, who are encouraged to act in a speculative setting. Their actions (or non-actions) have consciously meaningful outcomes, either immediately, or longer term. These outcomes are primarily social (e.g., meeting someone, acting in public), and emotional (e.g., feeling awkward, managing impressions), but are achieved and made accountable through their interaction with speculative materials and settings. Speculative Enactments thus require careful design, which create conditions for genuine social interactions to unfold, amidst elements of speculation. More than generating discourse, we will argue that these enactments stimulated participants actions and experiences in a way that invited empirical inquiry.

Participants are 'in' on the speculation (there is no intention to deceive) - but must interact with the premises of this speculation to generate outcomes in the world. As practical design work, they primarily involve stage setting and intervening in existing everyday routines. These allow for a grounded, but unscripted improvisation of particular futures. This paper emphasizes the process, interaction and experience with participants, but Speculative Enactments also produce a diversity of design research artifacts [65], which can be later presented as Design Fiction.

Speculative Enactments have been developed and refined through our own speculative practice. However, post-hoc, we relate most closely to Candy \& Dunagan's [18] description of Experiential Futures, which: "bridge the experiential gulf between inherently abstract notions of possible futures, and life as it is apprehended, felt, embedded and embodied in the present and on the ground."

Speculative Enactments are drawn from, and bear similarities to other approaches - most notably Odom et al.'s 'User Enactments' [60], Lindley's 'Anticipatory Ethnography' and the performance art of Blast Theory staged in collaboration with the Mixed Reality Lab [5]. We will return to this closely related, and complementary, work much more fully in the second half of the paper. First, however, we describe in detail three examples of Speculative Enactment we have undertaken.

\section{THREE SPECULATIVE ENACTMENTS IN PRACTICE}

A common thread across our projects has been an interest in the so-called 'Data-Driven Life' [82] as an anticipated phenomenon. Working as design researchers in HCI, we share an interest in the lived and socio-cultural experience of quantified lifestyles as they move beyond 'extreme users' [22] and pervade everyday life and popular culture. We ask future-oriented questions such as 'How will people remember their lives with such data?' and 'What would it be like were this data commonplace and public?' In Auger's terms [1], these 'futures' are alternative presents mostly concerned with new socio-technical configurations, as opposed to radical technological advances.

We now describe three distinct cases, which explore how Speculative Enactments can form part of a performance, an event, and a service. Presented chronologically, these chart our developing understanding of what makes a speculative enactment, and how they can work. Runner Spotters realizes the value in probing speculative experience by improvisation [21]; Metadating develops consequential social interaction; the Quantified Wedding project crystallized earlier insights to explore how to speculatively enact part of a service. Each of the projects we describe focuses on an anticipated phenomenon, which is framed with a speculation and then enacted in some consequential fashion with participants.

\section{Runner Spotters (2010)}

Chatting's Runner Spotters [21], the earliest project, foreshadowed many of the characteristics of Speculative Enactments. The project draws from improvisational acting to create performative and interactive modes of speculation with professional actors, which probe possible experience.

\section{The Speculation}

Runner Spotters investigates the implications of open streams of public data, in particular from fitness trackers. In 2010, the Nike+ was a leading commercial pedometer, which publicly broadcast an ID and running data (e.g. miles run, miles walked) over an unsecured wireless connection. The speculation in this project was of 'Runner Spotting' as a pastime (similar in principle to train or plane spotting) to spot habitual runners. Juxtaposed with well-understood concerns related to hacking or spying of personal data, this speculation sought to expose more complex, even ritualistic relationships with personal yet potentially public data. Speculation allowed the exploration of particular ethical and social questions about interacting with strangers' data.

\section{The Enactment}

The participants in this enactment were two improvisational actors and the design researcher as the director. The actors' jobs were advertised externally and conducted as paid work, over the course of three months and six sessions both were also experienced runners, Improv generally has been strongly advocated as a means of 'experience 
prototyping' [14], though in this case we adapted specific techniques from Johnstone's theatre sports [41]. The skill of the actor is to accept and integrate 'Given Circumstances' (from Stanislavski's method) to create a character with believable motivations. The actors accepted and incorporated the "offers" (situational, environmental, personal conditions) made to them by the director (the designer) to develop elaborated scenarios. For example, these might ask the actors to be shop assistants selling a 'Runner Spotting' device, or a young mum, using the device on a park bench. In this way, the 'designer-asdirector' responded, by suggesting and selecting - probing - interesting scenes. Iteration allowed multiple explorations of narrative and character development. Prepared underspecified improvisational props were used in various planned exercises as offers for the 'runner spotting' device, allowing form and function to be explored.

The actors predominantly worked in a performance space, however also undertook a pen and paper exercise of 'Runner Spotting' in a local park with real runners as a resource for later improvisation. This 'speculation by improvisation' [21] ultimately goes beyond the ideation of 'bodystorming' [64] or the empathizing of 'experience prototyping' [14]. The initial speculation of Runner Spotting became furnished with characters, dialogue, habits and narrative. These sessions were presented (mainly to design audiences) as a short film [20] and Design Fiction [6], with accompanying functional design artifacts.

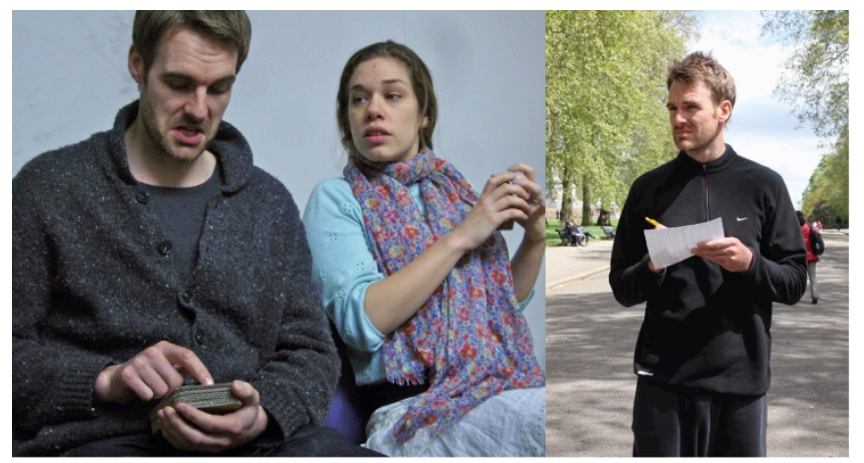

Figure 1: Runner Spotting, with props and in a public park.

Reflections- Acting Amidst Speculation

This enactment primarily highlights the benefits of adopting a performative and participatory approach to speculation. Runner Spotters required directing and designing circumstances - setting a stage - where skilled actors could believably construct that speculation with the designer. Working with these actors firstly led to a more developed, less superficial, resulting fictional narrative. But further, the responsive back and forth interaction with the actors created the opportunity to challenge the control of the designer, and one's own design/research orientation to the speculation at hand. Lastly, in requiring and making visible action, the speculative concept of Runner Spotting is encountered by both designer and actors as a place to act, rather than simply something to observe and pass comment on. Through the practice and direction of improv, the speculation is negotiated, played out and pushed towards boundaries. Through their performance, the speculative experience of runner spotting could be explored and iterated, as a resource for the designer/director.

\section{Analyzing Participant Experience}

We can approach experience in this enactment in two ways. On a surface level, we can consider the characters portrayed by the actors, arguing that the actors be able to probe the experience of the characters. They may be in a position to empathize and speak for these characters. We can also consider the experience of the actors as actors. We can begin to ask why and how these actors, and their characters, were engaging with this speculation in the way that they were. And what this tells us about the nature of the speculation itself - e.g. its probable or preferable nature; its relation to existing norms and values; the potential opportunities and challenges for design. As an RtD inquiry, such reflections informed a gamut of further design work. Alternatively, videoing each of the sessions allows a more formal qualitative analysis.

In some ways, Runner Spotting could be considered comparatively less consequential than other enactments. Yet we suggest there is more than just play-acting or roleplay here. These were skilled professionals doing paid work. Improv acting is by nature social and pressurized. The actors could not just 'say anything'. Successful improv relies on trust between the parties (director-actor; actoractor), and collaboration to produce a coherent character, dialogue and scene. Improv is a social game of developing consequence; each successive turn of the actors or director pushes the scene in a particular way, and demands something more of the others. Working with improv actors was in the first case a resource for the designer/director to co-construct and probe speculative narratives and experiences. But as an enactment, improv highlights the value of generating multiple moments of social performance, with participants acting amidst speculation.

\section{Metadating (2014)}

Metadating was a one-off event which further highlighted the value of social interaction amidst speculation, but with many more participants.

\section{The Speculation}

Metadating [32] sought to explore how quantified data relates to identity, and in particular how people would rehearse and perform identities around their data with others. We wanted to hear people talk about and with their data: to make jokes with it, to brag about it, to disavow it or defend it. We understood these everyday social interactions with data likely to exist, but felt they were challenging to engage in a research context in the wild. With the process of dating being a concentrated site of identity work, we speculated about a service for dating-with-data. What kind of data would be attractive? What would and wouldn't people share? How would people embellish data on a date? 


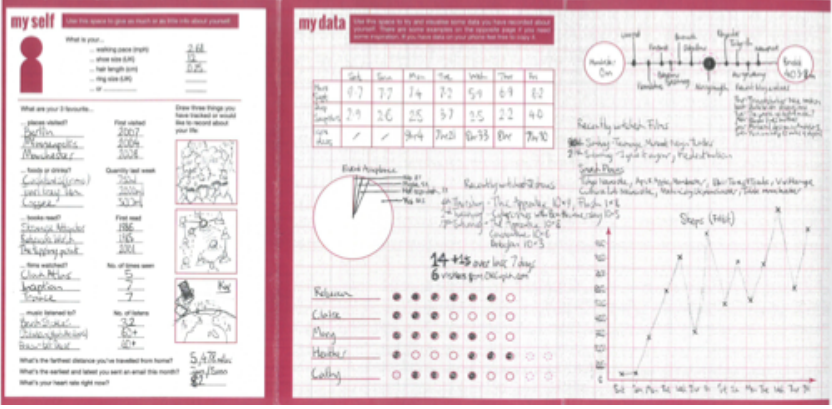

Figure 2: Completed Metadating data profile. The left hand side 'my self' includes quantified twists to common dating profile questions. Right hand side - 'my data' - represents hand-drawn data they tracked or chose to represent about themselves using the common infographic outlines provided.

The Enactment

Rather than making a dating website, or constructing a Design Fiction on the basis of our speculation, we chose to run a speed dating event. Crucially, this put live social interaction with data at the heart of our study, along with consequential experience. Metadating was advertised as a singles' dating and future-oriented research event. 11 [7M, 4F] single participants were invited to 'explore the romance of personal data'. After expressing their interest through a website, participants were posted a personal invite that included a blank 'data profile' to be crafted by hand in the week prior. These data profiles [Fig. 2], a form of cultural probe [36], became key functioning artifacts at the event.

While great care was taken in the setting, the advertising, and the communication around the event, the profiles did the most work to communicate the premise of our speculation and to suggest a diegesis to engage with. The profiles drew on familiar tropes of a dating profile to scaffold interaction, but presented a challenge to attendees that really mattered. Choosing data to represent oneself in an appropriate light required significant identity work, which participants would then have to talk about with strangers on a date. Our participants were for the most part deliberate about how they went about this. They could relate to the dating context and had prior experience of it.

On a Saturday evening in December 2014 guests were greeted with wine on arrival to a softly lit performance space on our campus. Metadating was principally a real dating event from the perspective of attendees. First, a mixed activity involved sharing first impressions of others' data profiles. Next, 28 four-minute speed-dates took place [Fig. 3]. The dates had no set structure, besides our suggestion to swap their data profiles at the start of each date. The success of the Metadating event turned on the candidness of participants. Something was really at stake in the context of the date to give a good impression of one's self; these were, after all, real speed dates. This immediate reality grounded the wider speculation at play. Underscoring the authenticity of the dates, one couple that met during the event began (and at time of writing continue) a long-term relationship.

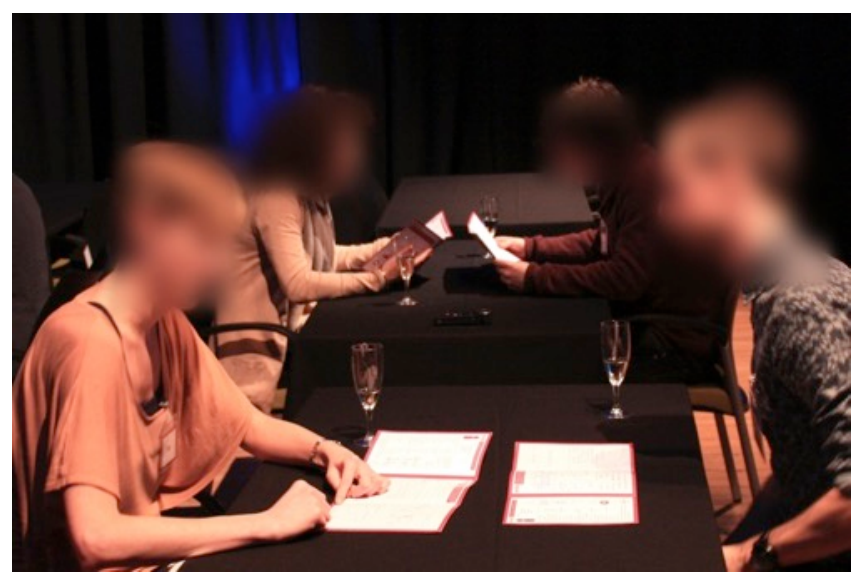

Figure 3: A genuine speed-date from the Metadating event.

Reflections - Circumstances for Social Interaction

Metadating briefly, and intensely, brought to life a range of possible human relationships to data. Data was transformed from a dry abstraction to a conduit of personal expression. Our speculation situated data as something to make jokes with rather than a mode of changing or nudging behaviour. Just as the actors and director ultimately created the characters and stories in Runner Spotters, so the resulting narrative, dialogue, and content of Metadating was elaborated by our participants. Our role as design researchers was to create a set of circumstances where such speculation was anchored in a familiar and relatable activity (speed dating) with meaning for the participants beyond taking part in research. As an enactment, Metadating emphasizes in particular the value of social interaction amidst speculation. Actors in Runner Spotters were accountable to themselves and the director; Metadating participants had to directly account for their interaction with the speculation to strangers on a date - a compelling opportunity for empirical investigation.

\section{Analyzing Participant Experience}

Details and findings from the Metadating event have been previously reported [30]. Here we highlight the empirical analysis that this event made possible. Copies of each data profile were preserved All dates, discussions and eight follow-up interviews were audio-recorded. More than opinions, or ideas which might have emerged from an interview about the concept, the social reality of the event invites ethnographic and discursive analysis.

Crucially, the insights and design implications from Metadating are not uniquely tied to the existence or otherwise of a quantified dating service. This was not an attempt at forecasting or evaluating a design proposal. Instead, we contest that while speculative, the enactment generated real, consequential, social interactions with data. And the understanding generated from this can then be used to inform the design of data services more generally. It does not matter if a 'Metadating' application ever becomes realized or not; it was real for 11 participants, on one evening. 


\section{Abacus Datagraphy: A Quantified Wedding (2016)}

More so than Runner Spotters, and Metadating, the Quantified Wedding project explored the design of a broader speculative service.

\section{The Speculation}

The project sought to explore themes of remembering with a 'Quantified Past' [31]; designing data as a lasting digital possession [44,61], technology heirlooms [58], and curating data related to important life events. Weddings are seen as unique, one-off events, and therefore any data collected at a wedding would likely be intended for remembering and sharing the day [54]; rather than to somehow optimize or record one's progress at getting married (or more alarmingly for the sake of comparison with the next one)! We speculated about 'wedding datagraphy' (as a parallel service to wedding photography) to professionally capture and curate meaningful and evocative data from a wedding. Over three months we undertook a design ethnography [69] of the wedding industry, in order to speculate on the design of different services, materials and branding for a speculative wedding datagraphy company - 'Abacus'.

\section{The Enactment}

However, rather than developing and deploying such a service in full, we focused our inquiry on designing and realizing one feature of the service as a particular enactment in which participants can become invested - an engaged couple meeting a 'wedding datagrapher'. At this meeting, couples would decide and agree the data they would like to collect from their upcoming wedding.

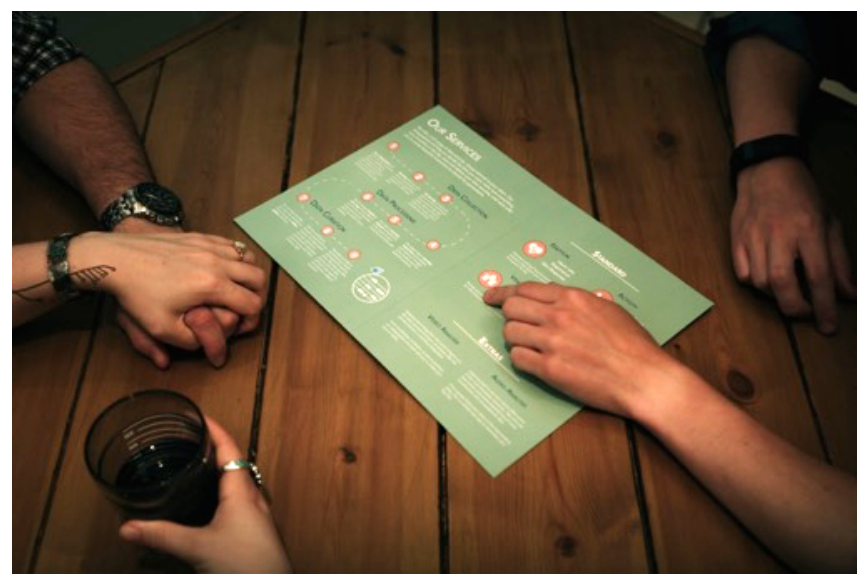

Figure 4: 'Mise-en-scene' promo image for meeting an Abacus Datagrapher, with a brochure introducing Abacus' services.

The wedding industry already trades on the fantastical and imaginative [54]. Consequentiality emerges through meeting couples together. Each participant moderates their interaction with speculation alongside their partner. However, in the interest of making an heirloom for the couple, and furthering their investment in the data they chose, we proposed to write a 'real-wedding' style magazine article about their imagined wedding. This would then be published, in a concept brochure for Abacus, to be kept by the couple, but also distributed more widely to publicise the concept. The magazine article provided a way to make concrete the otherwise speculative conversations we were having with our participants. They would also have something to keep from the enactment. As they chose not to be anonymized - this would also be a public, realworld representation of them at a significant time in their lives together. Lastly, the brochure would become a Design Fiction artifact in its own right, akin to fictional catalogues [56] and newspapers [63].

We developed an interactive and playful data catalogue as a set of Abacus Data Cards (Fig. 5). We piloted the structure of the enactment, and these cards in particular, through a set of 12 'pre-enactment interviews' with engaged and married people, as well as wedding industry workers.

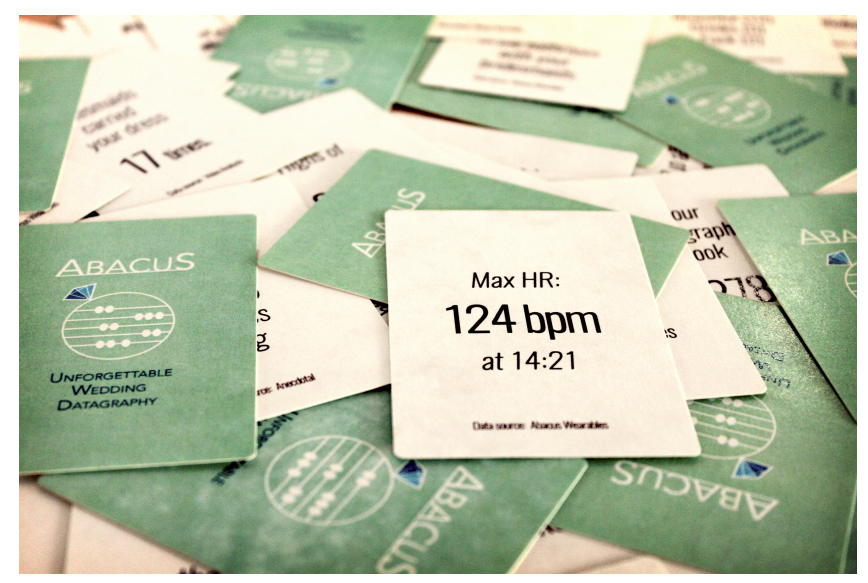

Figure 5: Abacus Data Cards, employed as an interactive catalogue of potential wedding data.

The highly personal, and bespoke nature of this enactment meant we sought only two engaged couples to take part. Whereas Metadating consisted of multiple short social interactions, this project emphasized an idiographic, personal relationship with our participants. Like Metadating, we posted couples a cultural probe activity, focused around the Abacus Data Cards. This did substantial work for us ahead of the enactment to establish the nature and terms of the speculation. Through their selective recruitment, and this activity, the couples were geared in to our speculation before we met.

The wedding datagrapher/researcher, in role, visited each couple twice. The first meeting revolved around discussing their upcoming wedding and the cards, to resolve between them what data they would choose to record, and what should be described in the article. The second meeting focused on the editing and discussion of the couple's realwedding article. This included a 500 word story, a large portrait photo of them and three further images of fictional 'data artifacts' to be produced after their wedding. Finally, both couples were posted the published wedding brochure, delivered inside 'Rock \& Roll Bride', a popular UK wedding magazine. Again, we do not report further findings here (see [30]), but reflect on the analytic process. 


\section{Reflections - Enacting a Service}

This project engaged in RtD speculation over a much longer period of time (six months) and with a broader brief. The study design and bespoke design process focused speculation on a particular evocative and consequential enactment. Rather than boundless imagination about weddings of the future, the enactment served to direct and productively constrain our RtD inquiry. Working with the 'datagrapher' role, we had to develop a design response to the initial conversation with our couples. From the content of the Abacus cards and articles, to the way we introduced the services and data artifacts, speculation was directed towards making the enactment meaningful to each couple.

\section{Analyzing Participant Experience}

Our design of the enactment was also with the aim of affording an Interpretive Phenomenological Analysis (IPA) [70] - that we have found especially suited to understanding individuals experiences of remembering their lives with technology. The couples excitedly rehearsed the story of their wedding to each other; they had to pick data they thought their partner would like; they anticipated sharing the brochure with friends. The three to four hours of recorded discussion with each couple, and reflections on our bespoke design process with them directly supported IPA. And yet, the final production of a concept brochure as Design Fiction (based on real weddings and narrative) also gives the speculation life beyond these highly personal enactments, inviting the broader discourse typical of most speculative work.

\section{DISTINGUISHING SPECULATIVE ENACTMENTS}

By presenting our three case examples, we have sought to foreground our own practice-led development of Speculative Enactments. In the remainder of this paper, we wish to carefully distinguish particular qualities of Speculative Enactments from many other speculative approaches. Through these distinctions we hope to tease out particular qualities and also limitations of each approach. More broadly, we suggest that these distinctions offer conceptual resources for HCI to reflect on how participants interact with and experience speculative design practice. Lastly, we will reflect on some practical guidelines.

\section{A) Speculative Enactments are consequential}

The single most defining quality of Speculative Enactments is that they generate circumstances where at least some elements or conditions of the speculation really matter to the participants. The actors in Runner Spotters were professionals developing an improvisation; Metadating attendees went on real dates; couples in the Quantified Wedding project had their stories published in a brochure.

This consequentiality attempts to address a fundamental challenge of futures work - that in its multiplicity $[18,80]$ the future is, as Candy notes, inherently abstract. Much of the design work entailed in speculation attempts to ground abstract or seemingly far off propositions (such as a 'datadriven life', or 'drone-based law enforcement' [47]).
Design Fiction in particular often relies on the careful crafting of a 'future mundane'. Bleecker's Near Future Laboratory aims to represent an 'everyday' future avoiding fantastical sci-fi, techno-utopia or dystopia. Present day media and materials (e.g. IKEA catalogues [13], documentary films [50,73], sports newspapers [63]) are employed to ground alternative presents and futures, and in Bruce Sterling's now-definitive terms "suspend disbelief about change" [10].

In some opposition to Design Fiction, is Wakkary et al.'s 'Material Speculation' [81]. The authors propose that it is necessary to establish a 'perceptual bridge' [1] between audience and fiction through actual, functioning artifacts, occupying space in the actual everyday world. Designs such as Pierce's inaccessible Obscura 1C camera [65], or Selby's Photobox [59] are described as counterfactual artifacts, which deviate sharply from familiar technologies. Over long periods of time participants are forced to speculate, reason and make sense of the actual presence of such artifacts in their lives.

Wakkary et al. [81] identify engaged interaction with these technologies as generative of speculation. But whereas their approach is tied ultimately to the materiality of a functioning, physical artifact, HCI has a rich history of performative work that can be used to widen the terms of participant engagement and experience. In particular, physical performance artists Blast Theory, in collaboration with the Mixed Reality Lab at the University of Nottingham, crafted carefully staged performance art inviting research that is "in the wild in the sense that [it] engages "real" users with emerging technologies in "real" settings under demanding conditions of actual use' [5]. Mixed reality games such as 'Uncle Roy' [3] or 'Can You See Me Now?' [2] notably compose compelling and consequential circumstances and trajectories of experience for public and participants around novel configurations of technology.

Speculative Enactments generate consequentiality through both counterfactual materials (e.g. data profiles and the Abacus cards) and demanding social performance (e.g. improv work, dates). The data profiles and 'real wedding' article were given to participants under demanding conditions, and demanded engagement with the speculation.

B) Speculative Enactments invite a study of experience Entirely bound up with consequentiality, we argue that Speculative Enactments create real social experiences with participants. These real experiences invite empirical analysis of participant actions and discourse amidst speculation. We wish to contrast this carefully with the discourse and participant experiences proposed by Lindley et al.'s 'Anticipatory Ethnography' [51] and Odom et al.'s 'User Enactments' [60].

Lindley et al. contest that good design fictions (giving the example of Spike Jonze movie Her) can 'situate the 
audience vicariously within the world of the film' and as such they may 'harbor the knowledge necessary to glean ethnographic insights'. Practically speaking, what is proposed is an 'afterglow' interview method, or larger scale audience analysis (e.g.[66]) on having watched the film.

We certainly can analyze discourse and commentary from different audiences generated by speculation, as Wong et al. [83] or Dalton et al. [25] have done. Indeed generating such discourse is the aim of most speculative work. HCI has a history of presenting provocative futures to participants to generate discourse (e.g., Mancini et al.'s 'Contravision' [53], Vines et al.'s 'Questionable Concepts' [77] and Lawson et al.'s fictional quantified pets websites [45]). However, Reeves [67] and Sterling [71] both note a vital caveat in all futures work; however sophisticated, any envisioning necessarily reflects our present concerns projected onto visions of the future.

Yet Anticipatory Ethnography seems to suggest that we can somehow skip ahead of time, and become vicarious participants in the futures represented. While the medium of film is a powerful tool for world-building, and the audiences can empathize strongly with characters and experiences in the film, the familiar, real-world experience the audience have is that of watching a film. They are necessarily one step removed, an audience to a fiction, rather than a participant of it. Candy \& Dunagan argue that Design Fiction struggles to bridge the "experiential gulf" to the future $[17,18]$.

Odom et al.'s 'User Enactments' (UE) [60,62] do however invite participants into a fiction of a kind. They require " $u$ sers to enact scenarios in which they get glimpses of several potential futures and to use their own experiences to critically make sense of what they encountered." These encounters bear some resemblance to high-fidelity Wizardof-Oz [24] or more scripted experience prototyping [14]. Props, dialogue and staging are very intentionally designed, in a lab setting, for carefully scripted encounters between participants, researchers, confederates and technologies. Participants must suspend disbelief about the scenario and technologies presented to them, and experience several 'what if?' or 'what would you do now?' encounters.

In some ways, UE allow the participant to interact with a carefully developed, but unresolved Design Fiction. However, the scripting used to probe particular values perhaps limits the participant's role and freedom in coconstructing the fiction. Further, the lab setting (however disguised) and rapid shift between multiple potential futures, risks breaking the suspension of disbelief, upon which the method partially relies. In contrast to the more consequential interactions with counterfactual material artifacts [81] and Blast Theory/ MRL work [5] participants are arguably playing along. Like Lindley's 'Anticipatory Ethnography', this is fieldwork for how-people-react-toand-talk-about futures - rather than their experience of these futures. UE and Design Fiction remain powerful generative methods. However, the essence of our critique is that we should be more ambitious in how participants can become meaningfully involved with speculation, and in Candy's terms, utilize the "continuum of human experience" [18].

Speculative Enactments are distinctive in prioritizing participant experience. We did not design a fictional dating website and then elicit participation with it. We designed a real dating experience grounded in speculative materials. The compelling nature of Metadating in particular, was that participants acted on and experienced speculation, beyond commenting on it. To be clear - we are not saying that we gave participants an experience of the future ahead of time. However, the experience that participants had, and that invites an ethnographic mode of analysis, informs us about existing hard-to-reach phenomena, or plausible, anticipated future phenomena. Of course it also generates speculative discourse before, during, and after the enactment.

\section{C) Participants are 'in' on and co-construct the fiction}

Speculative Enactments are concerned more with participants than audiences. There should be minimal, if any, 'smoke and mirrors' or behind-the-scenes work to manufacture a fictional set of circumstances. Part of the challenge of Speculative Enactments is to develop a scenario where the speculation becomes grounded, relevant and essentially makes sense to participants as a reality they can identify with. Our aim was not only that their interactions should be consequential, but also that they become invested in the experience. All three projects recruited selectively, and we relied on participants working for us (i.e. acting out scenes, making dating profiles, and editing an article).

Blast Theory's mixed reality games often rely on participants' trust in the experience, setting aside of skepticism, and also being unsighted as to what will happen next. This adds compelling drama and suspense to the experience, but where the participant is in a reactive mode. User Enactments are similar in this regard - participants have to rapidly respond to different scenarios, such as a smart home intervening to rearrange the school run. This carefully refined scripting is advantageous in probing particular values and responses, but diminishes the range of actions available to the participant and their stake in the overall narrative of the experience.

Denham-Cleaver and colleagues' 'Experience Design Theatre' [78] is an example of a participatory mode of speculative work, whereby an audience of different stakeholders in later life care became critics, directors and writers of several scenes articulating a future service. Participants' agency and opportunity to disagree about the appropriate direction of these scenes heightened their investment in the speculation presented.

We feel an affinity with Candy \& Dunagan's challenge of "designing circumstances or situations in which the 
collective intelligence and imagination of a community can come forth" [18]. We seek to design circumstances where participants are required to engage with the terms of the speculation, but in a wide-ranging fashion. There are particular moments during enactments where participants can improvise, and elaborate the fiction themselves. The speed dates were unstructured besides their time limit, and suggestion to swap profiles. Improv actors worked with under-specified cardboard prototypes, rather than the highly defined diegetic prototypes found in Design Fiction or particular design propositions of User Enactments.

\section{D) Stage-setting as world-building and RtD}

Much of the design work in Speculative Enactments involves the staging of the enactment. In practice, this entails a prolonged back and forth between designing materials (e.g. runner spotting devices, a data profile, Abacus data cards) and circumstances (e.g. improv sessions, a dating event, meeting a datagrapher). Both represent a practice of 'diegetic work', for elaborating, and allowing the elaboration of, a speculative story-world.

World-building in Design Fiction refers to the design of a context (social, political, environmental, technological and more) in which a 'diegetic prototype' (the speculative artifact) becomes plausible and makes sense. This takes on a slightly different meaning for Speculative Enactments. The world being built is not an entirely fictional one. Instead, the challenge is to construct a plausible set of circumstances or stage for the enactment to take place. Dunne \& Raby have argued gallery spaces suit the critical reflection intended for Critical Design [29]. We should question what the best staging is for any speculation with participants to take place. We did not want to simply ask people what data they would put on a dating profile or collect from their wedding. We developed a stage where doing so had outcomes and became consequential.

The circumstances, and material artifacts of enactments are mutually informing. This was especially true of probes and props introduced at the beginning of enactments. The Metadating data profile was designed for a particular set of circumstances - to be used on a speed date. But it simultaneously communicates (and invites speculation about) the possible nature of those circumstances.

Sturdee et al. [72] underline the value of such worldbuilding as RtD. Whether artifacts [46,76], narratives [25], films [40,50,74], research abstracts [7], websites [23] or any other means of world-building, speculative design reflects practice-based inquiry and commentary. Di Salvo et al.'s 'Speculative Civics' [26] exemplifies the diverse modes of speculative practice available to RtD.

We would also position the stage-setting of Speculative Enactments as RtD. However, world-building in Design Fiction explicitly requires the design of a narrative (even producing fictional research findings and papers $[33,49])$. In contrast, stage-setting of Speculative Enactments requires a constant translating and reframing of the speculation, from specific participants to broader audiences. We see parallels to Gaver et al.'s [37,39] description of the translational work required when involving on-street marketers, documentary filmmakers or other 'cultural commentators' in their projects. We see this as a highly productive constraint on speculative design; we are forced to repeatedly reflect on and rationalize how circumstances or materials should be designed to become plausible to real-world participants. The Abacus data cards were a response to developing a catalogue we could use flexibly with couples, that communicated the breadth and playfulness of data that could be collected about a wedding. We refined the form and use of these through our preinterviews to understand their plausibility.

Following Pierce's advocacy for the diversity of design research artifacts [65], we value the multiple material outcomes of this dialogical design process. In our case, these have variously included: branding, invites, props, cultural probe materials, adverts, workbooks, websites, social media postings, staged photographs, films, media articles [68] and magazines. Each of these does work to communicate and invite speculation. Some, such as letters and probes work solely with participants; others, like websites and media reaction [67], engage wider public discourse.

\section{E) Relying on existing routines as a future mundane}

An important aspect of Speculative Enactments in our practice has been to intervene in familiar routines and experiences. People watching, dating sites, weddings - all of these are familiar, indeed ritualized activities. They work as bridges in part because these are habits and indeed values that we can assume will probably exist in a recognizable form in the near-future. Secondly, they provide a familiar structure for participation, and in the case of weddings in particular, numerous departure and anchor points between reality and fiction. In some respect, intervening in this way recalls Harold Garfinkel's 'critical breaching' experiments [35] entailing breaching norms of everyday situations in order to probe the underlying nature and values of these norms. Dates are a well-understood activity, governed by numerous social norms. The highly familiar experience of engaged couples meeting wedding vendors motivated the enactment of 'meeting a wedding datagrapher'.

Situating Speculative Enactments in these routines shares the same rationale as Design Fiction - representing a future mundane. They suspend disbelief about these alternative circumstances, but also work as a helpful check on more wild utopian or dystopian futures. The Near Future Laboratory in particular emphasize the role of ethnography and fieldwork in their development of Design Fiction [57]. Likewise, Speculative Enactments require a thorough understanding of the domain in which they are to be situated, as a basis for reasoned speculation. 


\section{F) Practicing ethical enactments}

Any new approach should be reflective about their ethics. This is especially the case with Speculative Enactments as we argue these should be consequential to participants, and at best they should become in some way personally invested in the speculation. However, we believe there are a number of ways to ensure ethical enactments.

Firstly, participants are 'in' on the fiction. In our cases, their success did not depend on holding back any details of the enactments. Our participants were aware of who we were as researchers, and that these were research projects, even if we made efforts to avoid some of the conceptual baggage of 'just taking part in a research study'. Vitally, participants were able to provide fully informed consent. Participants were always able to withdraw or ask questions. Consequentiality should not be taken, or constructed in a pejorative light. We sought circumstances where investing in the speculation held value for our participants. They had the opportunity to meet a date; they received the magazine as a personal heirloom. Instructively, Benford et al. [4] have discussed at length the ethics of such performance-led work in-the-wild, particularly the need to do 'ethics throughout'; Speculative Enactments should also do this.

\section{GUIDELINES FOR SPECULATIVE ENACTMENTS}

We see Speculative Enactments as a developing approach based on our own practice, resources and research interests, but with broader applicability. Through critiquing the strengths and limitations of related speculative methods, we have sought to frame Speculative Enactments as a novel approach that prioritizes participants' social interactions and experiences. We aspire to this approach being open to appropriation rather than a prescribed method. That said, we offer the following practical guidelines for doing Speculative Enactments, and consider ways in which they draw upon and complement other methods.

\section{Designing the enactment}

1) Begin by identifying a speculation (e.g. a Quantified Wedding), which in broadest terms addresses your research questions or interests, around an anticipated phenomenon - such as remembering with data. In three rather different cases, we used Speculative Enactments to probe hard-toreach, alternative, or anticipated interactions with data. This was an explorative mode of design-led research - to open up new playgrounds for further study. Metadating did not lead us to develop a new dating app, but revealed to us the need for a range of new interactions for people to selectively curate, and socialize with, their data [32].

2) Do background research and design ethnography on the domain of your speculation (e.g. weddings). Begin developing design ideas and responses. Nova et al. [57] exemplify this approach in their Design Fiction. We have found design workbooks [38] useful for cataloguing, sharing and reflecting on developing ideas with colleagues. Start looking for touchpoints where participants could meaningfully encounter and engage with your speculation.
3) Consider ways in which you may enact parts of your speculation, and generate interesting experiences for participants, which demand performance and constructive actions from them (as with improv). The most challenging aspect of this is to design means to make this interaction consequential for participants. Metadating relies on the immediate accountability of a date; the Abacus brochure works longer term. Engaging multiple participants together can foster a social reality. Part of the attraction of doing Speculative Enactments is the opportunity to work closely with people, such as the actors in Runner Spotters, so embrace very personal or bespoke enactments if appropriate. Overall, the aim is to create conditions in which an abstract speculation becomes real and tractable, to a level that participants seriously invest in the enactment.

4) Continually prototype and pilot materials and presentations of your enactment. We made many sets of Abacus cards to understand how to talk about the range of data that could be recorded at a wedding. With colleagues and friends we evaluated the plausibility of our enactments - does it make sense and seem appealing to them? This is also an opportunity for early rounds of data-collection, or perhaps less structured user enactments; we recorded a number of scoping interviews with married and engaged colleagues about an early prototype of the Abacus cards. As a design practice, this may be a case of working until you find materials, and a set-up and presentation that 'feel right'. This working out is in itself is revealing of the nature of the speculation.

\section{Recruiting participants}

5) Decide on who the best participants could be and recruit selectively. For whom can you make this enactment most powerful, interesting or consequential? Engaged couples were well placed to imagine and engage with wedding services. Consider how many participants would be required - and how many you can practically work with. Our enactments have been quite small scale, but they allowed us to get to know to our participants. Larger scale enactments may also work, and should be explored.

6) Consider how to recruit these participants given what their participation would involve. View this recruitment as an opportunity to build a diegetic setting, and discuss your speculation with wider audiences. Participation in the enactment should be intrinsically motivated by the diegesis.

7) Be up-front with potential participants about what taking part in an enactment will entail. We have relied on participants emailing or completing a form with an 'expression of interest' then following up in person or via email with a longer explanation of the project. Speculative Enactments should not rely on smoke and mirrors to work.

8) Use cultural probes [36] or similar before meeting participants to communicate your seriousness and the broader terms of the speculation. These probes should not be generic, but fit your overall enactment. The Metadating 
data profile was an event invite. Abacus Datagraphy cards were a 'sample pack' from a new service. We have also argued that artifacts such as the Metadating data profile could be considered counterfactual, a form of Material Speculation [81]. Participants are required to reason about using data in an entirely novel way - to attract a date, rather than improve their wellbeing.

\section{Conducting the enactment}

9) Find an appropriate setting for your enactment. An event space can be carefully set up; someone's home might offer familiarity. Carefully plan for your own 'performative role' in the enactment (e.g. as director, host, datagrapher).

10) Think about what you can record about the event and the qualitative data and analysis this can produce. We have previously captured audio, photographs and materials. Be aware of how data collection (such as video) contributes to or compromises the consequential social interaction.

11) Overall, be attentive to the social reality and experience of your participants. How would they understand what they are doing? Taking part in a study? Meeting people? Doing professional work? What existing routines and understandings will they leverage in this enactment? The performative approaches of Blast Theory $[2,3]$ and Experience Design Theatre [78] are informative.

\section{Following the enactment}

12) Consider opportunities for post-hoc debriefing and reflection with participants 'off-stage' from the enactment. Afterwards, we considered a 'diary room' during the Metadating event. This can open up a wider discourse, and help in your own analysis and reflection on the enactment.

13) Consider strategies for presenting the outcomes of the enactment to wider audiences. This may be as a further public enactment (e.g. a wedding fair); as academic papers or exhibitions; or through social media and blog posts. However, most directly, as evidenced by the Runner Spotters film and the magazine produced for the Quantified Wedding project, Speculative Enactments can be generative of Design Fiction. Lastly, pay particular attention to how to engage with media interest [e.g. 68] and the potentiallly productive and unproductive misunderstandings that may arise [79] when communicating speculative work.

\section{Limitations and Next Steps}

There is an ephemeral quality to Speculative Enactments, as they carefully bring speculation to life for a small number of participants. These 'real' enactments can become more or less speculative through different forms of presentation. Doing a Speculative Enactment is clearly effortful. Rather than simply constructing fictional narratives, (as per much Design Fiction) they engage participants directly to generate their own speculative narratives. HCI should continue to work out when an imaginary abstract [7] will suffice, and when these longer, deeper speculative projects are most worthwhile.
Our guidelines are intended to be flexible and, we hope, invite significant refinement. The enactments shown here are all intimate, and one-offs. How could enactments be scaled up or repeated through multiple iterations? Could more interactive technology be employed alongside the printed and physical materials we have generally relied upon? What range of analytic foci could be brought to bear on enactments and how should this kind of practice be best documented and presented? By proposing Speculative Enactments to the CHI community, we hope to prompt the further development of not just this practice, but the role of participants in speculative design research more widely.

\section{FINAL REFLECTIONS}

In elucidating our developing practice of Speculative Enactments we hope to have provided more broadly a set of conceptual resources for reflecting on speculative research and practice in HCI. Speculative methods, and Design Fiction in particular have been successful in fostering critical and alternative design discourses in HCI. However, we believe it behooves us to continue to develop these methods as not only a mode of criticism, but also a productive way to address the kinds of pragmatic questions and challenges that the HCI field raises. Candy \& Dunagan's 'Experiential Futures' [18] chart a course for involving participants with speculation, in a way that goes beyond generating critical discourse with an audience. Speculative Enactments demonstrate through our own practice how these can be brought to bear in HCI. This also offers a critical reflection on speculative methods, by showing how they can be interrogated empirically.

Most significantly, we argue for the need to make speculation matter and be continually attentive to the nature of speculative experiences generated with participants. While we should be sober about what we are observing, this invites empirical analysis of those experiences, which exist at a rich boundary between speculation and reality. At the same time, Speculative Enactments are a form of practicebased inquiry and when given due consideration, a richly rewarding form of Research through Design. At their best, Speculative Enactments produce moments of compelling social reality, bringing plausible futures briefly to life.

\section{ACKNOWLEDGEMENTS}

We thank our participants, colleagues and anonymous reviewers who have been central to the development of Speculative Enactments. This work was partly performed as part of RCUK grant ES/M003574/1, funded through the Empathy and Trust in Online Communicating (EMoTICON) funding call administered by the Economic and Social Research Council in conjunction with the RCUK Connected Communities, Digital Economy and Partnership for Conflict, Crime and Security themes, and supported by the Defence Science and Technology Laboratory (Dstl) and the Centre for the Protection of National Infrastructure (CPNI). The third author was supported by the Leverhulme Trust (ECF-2012-642). 


\section{REFERENCES}

1. James Auger. 2013. Speculative design: crafting the speculation. Digital Creativity 24, 1: 11-35.

2. Steve Benford, Andy Crabtree, Martin Flintham, Adam Drozd, Rob Anastasi, Mark Paxton, Nick Tandavanitj, Matt Adams, and Ju Row-Farr. 2006. Can you see me now? ACM Transactions on Computer-Human Interaction (TOCHI) 13, 1: 100-133.

3. Steve Benford, Martin Flintham, Adam Drozd, Rob Anastasi, Duncan Rowland, Nick Tandavanitj, Matt Adams, Ju Row-Farr, Amanda Oldroyd, and Jon Sutton. 2004. Uncle Roy All Around You: Implicating the city in a location-based performance. Proc. Advances in Computer Entertainment (ACE 2004) 21: 47.

4. Steve Benford, Chris Greenhalgh, Bob Anderson, Rachel Jacobs, Mike Golembewski, Marina Jirotka, Bernd Carsten Stahl, Job Timmermans, Gabriella Giannachi, Matt Adams, and others. 2015. The ethical implications of HCI's turn to the cultural. $A C M$ Transactions on Computer-Human Interaction (TOCHI) 22, 5: 24.

5. Steve Benford, Chris Greenhalgh, Andy Crabtree, Martin Flintham, Brendan Walker, Joe Marshall, Boriana Koleva, Stefan Rennick Egglestone, Gabriella Giannachi, Matt Adams, and others. 2013. Performance-led research in the wild. $A C M$ Transactions on Computer-Human Interaction (TOCHI) 20, 3: 14.

6. Julian Bleecker. 2009. Design Fiction: A short essay on design, science, fact and fiction. Near Future Laboratory 29.

7. Mark Blythe. 2014. Research Through Design Fiction: Narrative in Real and Imaginary Abstracts. In Proceedings of the SIGCHI Conference on Human Factors in Computing Systems (CHI '14), 703-712. https://doi.org/10.1145/2556288.2557098

8. Mark Blythe, Kristina Andersen, Rachel Clarke, and Peter Wright. 2016. Anti-Solutionist Strategies: Seriously Silly Design Fiction. In Proceedings of the 2016 CHI Conference on Human Factors in Computing Systems (CHI '16), 4968-4978. https://doi.org/10.1145/2858036.2858482

9. Mark Blythe, Jamie Steane, Jenny Roe, and Caroline Oliver. 2015. Solutionism, the Game: Design Fictions for Positive Aging. In Proceedings of the 33rd Annual ACM Conference on Human Factors in Computing Systems, 3849-3858. http://dx.doi.org/10.1145/2702123.2702491
10. Torie Bosch and Jacob Brogan. 2012. Sci-Fi Writer Bruce Sterling Explains the Intriguing New Concept of Design Fiction. Slate.

Retrieved September 16, 2016 from http://www.slate.com/blogs/future tense/2012/03/02/b ruce_sterling_on_design_fictions_.html

11. Eva Brandt and Camilla Grunnet. 2000. Evoking the future: Drama and props in user centered design. In Proceedings of Participatory Design Conference (PDC 2000), 11-20.

12. Pam Briggs, Mark Blythe, John Vines, Stephen Lindsay, Paul Dunphy, James Nicholson, David Green, Jim Kitson, Andrew Monk, and Patrick Olivier. 2012. Invisible Design: Exploring Insights and Ideas Through Ambiguous Film Scenarios. In Proceedings of the Designing Interactive Systems Conference (DIS '12), 534-543. https://doi.org/10.1145/2317956.2318036

13. Barry Brown. 2015. IKEA Design Fiction Catalogue. Retrieved September 20, 2016 from http://mobilelifecentre.org/sites/default/files/Design_Fi ction_IKEA_2015.pdf

14. Marion Buchenau and Jane Fulton Suri. 2000. Experience Prototyping. In Proceedings of the $3 \mathrm{rd}$ Conference on Designing Interactive Systems: Processes, Practices, Methods, and Techniques (DIS '00), 424-433. https://doi.org/10.1145/347642.347802

15. Bernhard E. Bürdek. 2005. Design: History, theory and practice of product design. Walter de Gruyter.

16. Laura Buttrick, Conor Linehan, Ben Kirman, and Dan O'Hara. 2014. Fifty Shades of CHI: The Perverse and Humiliating Human-computer Relationship. In $\mathrm{CHI}$ '14 Extended Abstracts on Human Factors in Computing Systems (CHI EA '14), 825-834. https://doi.org/10.1145/2559206.2578874

17. Stuart Candy. 2010. The futures of everyday life: politics and the design of experiential scenarios.

18. Stuart Candy and Jake Dunagan. Designing an experiential scenario: The People Who Vanished. Futures. https://doi.org/10.1016/j.futures.2016.05.006

19. John M. Carroll (Ed.). 1995. Scenario-Based Design: Envisioning Work and Technology in System Development. John Wiley \& Sons, Inc., New York, NY, USA. http://dl.acm.org/citation.cfm?id=209227

20. David Chatting. 2010. Runner Spotters. Retrieved September 20, 2016 from http://davidchatting.com/runninglives/spotters/

21. David Chatting. 2014. Speculation by Improvisation. In DIS 2014 Workshop on Human-Computer Improvisation. Retrieved September 21, 2015 from 
http:/openlab.ncl.ac.uk/hcimprovisation/files/2014/06/ chatting-improv-v2.pdf

22. Eun Kyoung Choe, Nicole B. Lee, Bongshin Lee, Wanda Pratt, and Julie A. Kientz. 2014. Understanding Quantified-selfers' Practices in Collecting and Exploring Personal Data. In Proceedings of the SIGCHI Conference on Human Factors in Computing Systems (CHI '14), 1143-1152. https://doi.org/10.1145/2556288.2557372

23. Peter Cook. 1999. Archigram. Princeton Architectural Press.

24. Nils Dahlbäck, Arne Jönsson, and Lars Ahrenberg. 1993. Wizard of Oz studies: why and how. In Proceedings of the 1st international conference on Intelligent user interfaces, 193-200. http://dx.doi.org/10.1145/169891.169968

25. Nicholas S. Dalton, Rebecca Moreau, and Ross K. Adams. 2016. Resistance is Fertile: Design Fictions in Dystopian Worlds. In Proceedings of the 2016 CHI Conference Extended Abstracts on Human Factors in Computing Systems (CHI EA '16), 365-374. https://doi.org/10.1145/2851581.2892572

26. Carl DiSalvo, Tom Jenkins, and Thomas Lodato. 2016. Designing Speculative Civics. In Proceedings of the 2016 CHI Conference on Human Factors in Computing Systems (CHI '16), 4979-4990. https://doi.org/10.1145/2858036.2858505

27. Paul Dourish and Genevieve Bell. 2014. "Resistance is futile": reading science fiction alongside ubiquitous computing. Personal and Ubiquitous Computing 18, 4: 769-778.

28. Anthony Dunne. 1999. Hertzian tales. MIT Press.

29. Anthony Dunne and Fiona Raby. 2013. Speculative everything: design, fiction, and social dreaming. MIT Press.

30. Chris Elsden, Abigail C. Durrant, David Chatting, David Green, and David S. Kirk. 2017. Abacus Datagraphy: A Speculative Enactment. In Proceedings of the 3rd Biennial Research Through Design Conference. 2017. (Forthcoming).

31. Chris Elsden, David S. Kirk, and Abigail C. Durrant. 2015. A Quantified Past: Toward Design for Remembering With Personal Informatics. HumanComputer Interaction 0, 0: 1-40.

https://doi.org/10.1080/07370024.2015.1093422

32. Chris Elsden, Bettina Nissen, Andrew Garbett, David Chatting, David Kirk, and John Vines. 2016. Metadating: Exploring the Romance and Future of Personal Data. In Proceedings of the 2016 CHI Conference on Human Factors in Computing Systems
(CHI'16), 685-698. https://doi.org/10.1145/2858036.2858173

33. Enrique Encinas and Mark Blythe. 2016. The Solution Printer: Magic Realist Design Fiction. In Proceedings of the 2016 CHI Conference Extended Abstracts on Human Factors in Computing Systems (CHI EA '16), 387-396.

https://doi.org/10.1145/2851581.2892589

34. Christopher Frayling. 1993. Research in art and design.

35. Harold Garfinkel and Harold Garfinkel. 1984. Studies in ethnomethodology.

36. William Gaver, Tony Dunne, and Elena Pacenti. 1999. Design: Cultural Probes. interactions 6, 1: 21-29. https://doi.org/10.1145/291224.291235

37. William Gaver. 2007. Cultural commentators: Nonnative interpretations as resources for polyphonic assessment. International journal of human-computer studies 65, 4: 292-305.

38. William Gaver. 2011. Making Spaces: How Design Workbooks Work. In Proceedings of the SIGCHI Conference on Human Factors in Computing Systems (CHI'11), 1551-1560. https://doi.org/10.1145/1978942.1979169

39. William Gaver, Andy Boucher, Nadine Jarvis, David Cameron, Mark Hauenstein, Sarah Pennington, John Bowers, James Pike, Robin Beitra, and Liliana Ovalle. 2016. The Datacatcher: Batch Deployment and Documentation of 130 Location-Aware, Mobile Devices That Put Sociopolitically-Relevant Big Data in People's Hands: Polyphonic Interpretation at Scale. In Proceedings of the 2016 CHI Conference on Human Factors in Computing Systems (CHI '16), 1597-1607. https://doi.org/10.1145/2858036.2858472

40. Sabrina Hauser, Audrey Desjardins, and Ron Wakkary. 2014. Sfuture: Envisioning a Sustainable University Campus in 2065. In Proceedings of the 2014 Companion Publication on Designing Interactive Systems (DIS Companion '14), 29-32. https://doi.org/10.1145/2598784.2602774

41. Keith Johnstone. 2014. Impro for storytellers. Routledge.

42. Kenji Kawakami. 1995. 101 unuseless Japanese inventions: the art of Chindogu. WW Norton \& Company.

43. Jofish Kaye and Paul Dourish. 2014. Special issue on science fiction and ubiquitous computing. Personal and Ubiquitous Computing 18, 4: 765-766.

44. Joseph'Jofish' Kaye, Janet Vertesi, Shari Avery, Allan Dafoe, Shay David, Lisa Onaga, Ivan Rosero, and Trevor Pinch. 2006. To have and to hold: exploring the personal archive. In Proceedings of the SIGCHI 
conference on Human Factors in computing systems, 275-284.

http://dx.doi.org/10.1145/1124772.1124814

45. Shaun Lawson, Ben Kirman, Conor Linehan, Tom Feltwell, and Lisa Hopkins. 2015. Problematising Upstream Technology Through Speculative Design: The Case of Quantified Cats and Dogs. In Proceedings of the SIGCHI Conference on Human Factors in Computing Systems (CHI '15) 2663-2672. https://doi.org/10.1145/2702123.2702260

46. Joseph Lindley. 2015. Crypto Heater: A Design Fiction. In Proc. of the 2015 ACM SIGCHI Conference on Creativity and Cognition (C\&C '15), 355-356. https://doi.org/10.1145/2757226.2757367

47. Joseph Lindley and Paul Coulton. 2015. Game of Drones. In Proceedings of the 2015 Annual Symposium on Computer-Human Interaction in Play (CHI PLAY '15), 613-618. https://doi.org/10.1145/2793107.2810300

48. Joseph Lindley and Paul Coulton. 2015. Back to the Future: 10 Years of Design Fiction. In Proceedings of the 2015 British HCI Conference (British HCI '15), 210-211. https://doi.org/10.1145/2783446.2783592

49. Joseph Lindley and Paul Coulton. 2016. Pushing the Limits of Design Fiction: The Case For Fictional Research Papers. In Proceedings of the 2016 CHI Conference on Human Factors in Computing Systems (CHI'16), 4032-4043.

https://doi.org/10.1145/2858036.2858446

50. Joseph Lindley and Robert Potts. 2014. A Machine Learning: An Example of HCI Prototyping with Design Fiction. In Proceedings of the 8th Nordic Conference on Human-Computer Interaction: Fun, Fast, Foundational (NordiCHI '14), 1081-1084. https://doi.org/10.1145/2639189.2670281

51. Joseph Lindley, Dhruv Sharma, and Robert Potts. 2015. Anticipatory Ethnography: Design Fiction as an Input to Design Ethnography. In Proceedings of Ethnographic Praxis in Industry Conference 2015. http://onlinelibrary.wiley.com/doi/10.1111/15598918.01030/abstract

52. Conor Linehan, Ben J. Kirman, Stuart Reeves, Mark A. Blythe, Joshua G. Tanenbaum, Audrey Desjardins, and Ron Wakkary. 2014. Alternate Endings: Using Fiction to Explore Design Futures. In CHI '14 Extended Abstracts on Human Factors in Computing Systems (CHI EA '14), 45-48. https://doi.org/10.1145/2559206.2560472

53. Clara Mancini, Yvonne Rogers, Arosha K. Bandara, Tony Coe, Lukasz Jedrzejczyk, Adam N. Joinson, Blaine A. Price, Keerthi Thomas, and Bashar
Nuseibeh. 2010. Contravision: Exploring Users' Reactions to Futuristic Technology. In Proceedings of the SIGCHI Conference on Human Factors in Computing Systems (CHI '10), 153-162. https://doi.org/10.1145/1753326.1753350

54. Michael Massimi, Richard Harper, and Abigail J. Sellen. 2014. "Real, but Glossy": Technology and the Practical Pursuit of Magic in Modern Weddings. In Proceedings of the 17th ACM Conference on Computer Supported Cooperative Work \& Social Computing (CSCW'14), 854-865. https://doi.org/10.1145/2531602.2531682

55. Norbert Müllert and Robert Jungk. 1987. Future Workshops: How to create desirable futures. London, United Kingdom: Institute for Social Inventions.

56. Near Future Laboratory. 2014. TBD Catalog. Retrieved September 20, 2016 from http://tbdcatalog.com/

57. Nicolas Nova, Katherine Miyake, NANCY KWON, and WALTON CHIU. 2013. Curious rituals: Gestural interaction in the digital everyday. In Ethnographic Praxis in Industry Conference Proceedings, 406-406. http://onlinelibrary.wiley.com/doi/10.1111/j.15598918.2013.00035.x/full

58. William Odom, Richard Banks, David Kirk, Richard Harper, Siân Lindley, and Abigail Sellen. 2012. Technology heirlooms?: considerations for passing down and inheriting digital materials. In Proceedings of the 2012 ACM annual conference on Human Factors in Computing Systems, 337-346. http://dx.doi.org/10.1145/2207676.2207723

59. William Odom, Mark Selby, Abigail Sellen, David Kirk, Richard Banks, and Tim Regan. 2012. Photobox: on the design of a slow technology. In Proc. of the Designing Interactive Systems Conference, 665-668. http://dx.doi.org/10.1145/2317956.2318055

60. William Odom, John Zimmerman, Scott Davidoff, Jodi Forlizzi, Anind K. Dey, and Min Kyung Lee. 2012. A Fieldwork of the Future with User Enactments. In Proceedings of the Designing Interactive Systems Conference (DIS '12), 338-347. https://doi.org/10.1145/2317956.2318008

61. William Odom, John Zimmerman, and Jodi Forlizzi. 2014. Placelessness, spacelessness, and formlessness: experiential qualities of virtual possessions. In Proceedings of the 2014 conference on Designing interactive systems, 985-994. http://dx.doi.org/10.1145/2598510.2598577

62. William Odom, John Zimmerman, Jodi Forlizzi, Hajin Choi, Stephanie Meier, and Angela Park. 2014. Unpacking the Thinking and Making Behind a User Enactments Project. In Proceedings of the 2014 
Conference on Designing Interactive Systems (DIS '14), 513-522. https://doi.org/10.1145/2598510.2602960

63. John O'Shea and Scott Smith. 2014. Winning Formula. FutureEverything. Retrieved September 20, 2016 from http://futureeverything.org/events/winning-formula/

64. Antti Oulasvirta, Esko Kurvinen, and Tomi Kankainen. 2003. Understanding Contexts by Being There: Case Studies in Bodystorming. Personal Ubiquitous Comput. 7, 2: 125-134. https://doi.org/10.1007/s00779-003-0238-7

65. James Pierce. 2014. On the Presentation and Production of Design Research Artifacts in HCI. In Proceedings of the 2014 Conference on Designing Interactive Systems (DIS '14), 735-744. https://doi.org/10.1145/2598510.2598525

66. Rachel Quirk, Martin Olver, Max Hammond, and Claire Davies. 2008. The Guide to Researching Audiences. JISC Strategic Content Alliance. Available at http://sca. jiscinvolve.org/wp/2009/02/05/downloadaudienceanalysis-toolkit.

67. Stuart Reeves. 2012. Envisioning Ubiquitous Computing. In Proceedings of the SIGCHI Conference on Human Factors in Computing Systems (CHI '12), 1573-1582. https://doi.org/10.1145/2207676.2208278

68. Aviva Rutkin. 2016. Dating by numbers. New Scientist 230, 3070: 22.

69. Tony Salvador, Genevieve Bell, and Ken Anderson. 1999. Design ethnography. Design Management Journal (Former Series) 10, 4: 35-41.

70. Jonathan A. Smith, Paul Flowers, and Michael Larkin. 2009. Interpretative phenomenological analysis: Theory, method and research. Sage.

71. Bruce Sterling. 2010. Keynote: Bruce Sterling (us) on Atemporality $\mid$ transmediale. https://transmediale.de/keynote-bruce-sterling-usatemporality

72. Miriam Sturdee, Paul Coulton, Joseph G. Lindley, Mike Stead, Haider Ali, and Andy Hudson-Smith. 2016. Design Fiction: How to Build a Voight-Kampff Machine. In Proceedings of the 2016 CHI Conference Extended Abstracts on Human Factors in Computing Systems, 375-386. http://dx.doi.org/10.1145/2851581.2892574

73. Superflux. 2011. Song of the Machine. Retrieved September 20, 2016 from http://superflux.in/work/song-machine

74. Superflux. 2015. Uninvited Guests. Retrieved September 20, 2016 from http://superflux.in/work/uninvited-guests
75. Joshua Tanenbaum, Karen Tanenbaum, and Ron Wakkary. 2012. Steampunk As Design Fiction. In Proceedings of the SIGCHI Conference on Human Factors in Computing Systems (CHI '12), 1583-1592. https://doi.org/10.1145/2207676.2208279

76. Diego Trujillo-Pisanty. 2010. With Robots. Retrieved September 20, 2016 from http://www.trujillodiego.com/work/withrobots.html

77. John Vines, Mark Blythe, Stephen Lindsay, Paul Dunphy, Andrew Monk, and Patrick Olivier. 2012. Questionable Concepts: Critique As Resource for Designing with Eighty Somethings. In Proceedings of the SIGCHI Conference on Human Factors in Computing Systems (CHI '12), 1169-1178. https://doi.org/10.1145/2207676.2208567

78. John Vines, Tess Denman-Cleaver, Paul Dunphy, Peter Wright, and Patrick Olivier. 2014. Experience Design Theatre: Exploring the Role of Live Theatre in Scaffolding Design Dialogues. In Proceedings of the SIGCHI Conference on Human Factors in Computing Systems (CHI '14), 683-692. https://doi.org/10.1145/2556288.2556960

79. John Vines, Anja Thieme, Rob Comber, Mark Blythe, Peter C. Wright, and Patrick Olivier. 2013. HCI in the Press: Online Public Reactions to Mass Media Portrayals of HCI Research. In Proceedings of the SIGCHI Conference on Human Factors in Computing Systems (CHI '13), 1873-1882. https://doi.org/10.1145/2470654.2466247

80. Joseph Voros. 2003. A generic foresight process framework. foresight 5, 3: 10-21.

81. Ron Wakkary, William Odom, Sabrina Hauser, Garnet Hertz, and Henry Lin. 2015. Material speculation: Actual artifacts for critical inquiry. Aarhus Series on Human Centered Computing 1, 1: 12.

82. Gary Wolf. 2010. The data-driven life. The New York Times 28. Retrieved Sep 20th, 2016 from http://www.nytimes.com/2010/05/02/magazine/02selfmeasurement-t.html

83. Richmond Y. Wong and Deirdre K. Mulligan. 2016. When a Product Is Still Fictional: Anticipating and Speculating Futures Through Concept Videos. In Proceedings of the 2016 ACM Conference on Designing Interactive Systems (DIS '16), 121-133. https://doi.org/10.1145/2901790.2901801

84. John Zimmerman, Jodi Forlizzi, and Shelley Evenson. 2007. Research through design as a method for interaction design research in HCI. In Proceedings of the SIGCHI Conference on Human Factors in Computing Systems (CHI '07), 439-502. http://dx.doi.org/10.1145/1240624.1240704 